\title{
Investigation of Affecting Factors on Persistence in the Treatment of Patients under Methadone Maintenance Therapy in Addiction Therapy Centers, Yazd-Iran
}

\author{
Mohammad Reza Vafaeinasab1, Mohammad Hadi Farahzadi2*, \\ Omran Mohammad Razaghi3 ${ }^{3}$, Reza Ali Fallahzadeh4, Mohammad Hasan Lotfi ${ }^{5}$, \\ Shahin Akhondzadeh 6 \\ ${ }^{1}$ Faculty of Medicine, Shahid Sadoughi University of Medical Sciences, Yazd, Iran \\ ${ }^{2}$ Department of Neuroscience, Faculty of Advanced Technologies in Medicine, Tehran University of Medical \\ Sciences, Tehran, Iran \\ ${ }^{3}$ Faculty of Medicine, Tehran University of Medical Sciences and Health Services, Tehran, Iran \\ ${ }^{4}$ Department of Environmental Health, Faculty of Public Health, Shahid Sadoughi University of Medical Sciences, \\ Yazd, Iran \\ ${ }^{5}$ Faculty of Public Health, Shahid Sadoughi University of Medical Sciences, Yazd, Iran \\ ${ }^{6}$ Psychiatric Research Center, Roozbeh Hospital, Tehran University of Medical Sciences, Tehran, Iran \\ Email: ${ }^{*}$ dr.farahzadi@yahoo.com
}

Received 27 March 2015; accepted 17 May 2015; published 20 May 2015

Copyright (C) 2015 by authors and Scientific Research Publishing Inc.

This work is licensed under the Creative Commons Attribution International License (CC BY).

http://creativecommons.org/licenses/by/4.0/

(c) (i) Open Access

\section{Abstract}

Drug addiction is one of the current world's hygienic, mental and social problems. There are different treatments for this illness. MMT (Methadone Maintenance Therapy) is considered as a standard and acceptable therapy for addiction; and there are many affecting factors regarding gaining success in this type of treatment. In this study, we investigated some of these factors. One of the most important issues in MMT is to keep up patient on his/her treatment till complete abstinence; therefore, it is recommended that the patient does not leave his/her therapy without discretion of the therapist. In this study, 230 patients, who began MMT, and admitted to addiction treatment centers of Yazd province were included. In this study, the survival rate in the first, third, and sixth months were evaluated as $93.9 \%, 63.48 \%$, and $28.36 \%$, respectively. It was found that following parameters are important in rate of survival during treatment: family support, gender, dose of methadone and concomitant use of morphine during treatment. Moreover, factors like level of education, marital status, age and concomitant use of methamphetamine during treatment

\footnotetext{
${ }^{*}$ Corresponding author.
}

How to cite this paper: Vafaeinasab, M.R., Farahzadi, M.H., Razaghi, O.M., Fallahzadeh, R.A., Lotfi, M.H. and Akhondzadeh, S. (2015) Investigation of Affecting Factors on Persistence in the Treatment of Patients under Methadone Maintenance Therapy in Addiction Therapy Centers, Yazd-Iran. Health, 7, 606-616. http://dx.doi.org/10.4236/health.2015.75072 
can be effective in this regard.

\section{Keywords}

MMT, Addiction, Persistence in the Treatment, Yazd

\section{Introduction}

Drug addiction is one of the current world's hygienic, mental and social problems. The dilemma of drug abuse and its dependency is now considered as a complicated and multifaceted issue. The reasons for drug use are completely diverse and stem from a variety of factors including social, economic, interpersonal and personal ones, and hence it is often difficult to identify its main causes. In many times, solving this problem is more difficult than understanding its causes and facilitating factors.

There are different treatments for this illness. MMT is considered as a standard and acceptable therapy for addiction; and there are many affecting factors regarding gaining success in this type of treatment. In this study, we investigated some of these factors. One of the most important issues in MMT is to keep up patient on his/her treatment till complete abstinence; therefore, it is recommended that the patient does not leave his/her therapy without discretion of the therapist.

In recent years, many patients have been referred to addiction therapy centers for treatment and many of them have being engaged in the MMT; however, this program like any other one needs monitoring and evaluation in order to fix any problems, and keep it in a level of utmost effectiveness and sophistication.

Although methadone maintenance therapy is a well-known approach to the treatment of drug use disorders and harm reduction. But the main challenge is retention rate in MMT methods.

Several studies have examined the survival of patients in methadone maintenance therapy. Hosseini and colleagues showed that relapse rate was $3.3 \%$ in the first month, $13.9 \%$ in three months, $23.2 \%$ in six months, $31.7 \%$ in first year and $41.7 \%$ was a total relapse rate. Survival rate had a direct significant statistical relationship with the age, type of drug and method of use [1]. Daniela and colleagues showed that the retention rate after 1 year was 40\% for patients in methadone maintenance, 18\% in naltrexone and 15\% in drug-free program. For patients in maintenance, methadone dosage and clinic policy were the most important factors for retention [2].

Robert E. Booth et al. have demonstrated that $60 \%$ of patients remained for at least 90 days. Factors associated with retention included higher methadone dose, free treatment, greater contacts with the clinic and counselor rating of patient cooperation [3]. Einat Peles and colleagues have indicated that the 1-year retention rate was 74.4\%. Factors predicting prolonged retention in MMT treatment (Cox regression) were daily methadone dose of $100 \mathrm{mg}$ or greater, negative urine for opiates after 1 year, and being a parent on admission [4].

According to the analyzed data in Karimi Talabari et al.'s study, treatment system, the patients, and the family are three effective factors in dropping out and bands of these factors influence on each other. The patient encounters with issues including low motivation, unstable motivation, and comorbid psychiatric disorders. On the other hand, the family is not conversant about technique's treatment; therefore, they do not cooperate adequately. Also treatment system regarding many aspects (such as protocol inaccuracy, labeling, contemptuous behavior with client, and undertaking behavior with patient for example seeing him as a wrongdoer person, not to inform him, lack of enough appointment and empathy with him) is unaffordable for client. In this system, quantity is more emphasized than quality and psychological treatment is too colorless [5].

In this study, 230 patients, who began MMT, and admitted to addiction treatment centers of Yazd province were included; hence the flowing parameters were evaluated: their demographics, family background, judicial record, mental and physical illness, risky behaviors, records of the drug use and previous treatments, dose of methadone use in several weeks of therapy, existence of positive test index for methamphetamine, and morphine during treatment period, being absence in therapy routine and discontinuation of treatment. Moreover, the survival rates of patients at the end of the first, the third, and the sixth months were calculated. Unlike other studies, in this study the efficiency of family collaboration was evaluated. Information about the parameters like a) family knowledge about the disease, b) the participation of families in family therapy sessions, and c) family attitudes about the efficacy of MMT evaluated through the questionnaires. 


\section{Materials and Methods}

\subsection{Participants}

This study is an analysis based on uncontrolled prospective cohort method. 230 patients with a record of opiates' consumption who took part in methadone maintenance treatment (MMT) program based on Health Department and Indication Therapy Protocol, and referred to addiction treatment centers of Yazd province to initiate their treatment process were participated in this study. This project has approved by Hygiene College Ethics Committee of Tehran University of Medical Science. All participants have filled out the satisfaction form for participation in this study.

\subsection{Measurements}

At the beginning of the study the goals were described for them and for each patient the MAP questionnaire (Maudsley Addiction Profile) (Appendix), that is attached here, was completed [6]. The questionnaire examined the demographic, family, juridical records, along with physical and mental illnesses, risky behavior, drug use history and previous treatment records.

During the treatment patients were followed by a one-page-form, attached here. Moreover, following information were also investigated: dose of methadone consumption at different weeks, positive morphine and methamphetamine test, absence of therapy and discontinuation of treatment. In addition, therapy survival rates of patients in the first, third and sixth months were calculated. For getting more confidence data entry procedure was done by the formal physician or consultant. Diagnostic tests were done by using rapid diagnostic tests of morphine and methamphetamine; these tests are commonly used in the market and the centers [7].

\subsection{Statistical Analysis}

Information obtained in the SPSS software were feed to computer and required indicators were obtained and Chi-square test and survival analysis methods, and Log-rank and Kaplan-Meier curves were used for conclusions.

\section{Results}

Among 230 patients were enrolled in the study 225 (97.8\%) and 5 (2.2\%) were male and female respectively; with an average age of 35 years (11 to 67 years). 47 patients (20.4\%) use only opium; 20\% (8.7\%) use heroin; and $8 \%$ (3.5\%) use opium-juice (Shiree); 2 (0.9\%) use methamphetamine; and one person (0.4\%) uses alcohol; moreover 152 individuals (66\%) use multiple addictive-drugs. 111 patients (48.3\%) took advantage of their family cooperation during treatment phase; however, 118 patients (51.3\%) did not show appropriate cooperate with their family. 48 patients (20.9\%) had a prison record; yet 182 individuals (79.1\%) did not mention imprisonment experience.

During treatment with different doses of methadone patients had reached a stable state. 10 patients (4.3\%) use less than $50 \mathrm{mg}$ of methadone daily; 175 (76.1\%) use between 50 to $100 \mathrm{mg}$ of methadone on a daily basis; 43 (18.7\%) use 100 - $150 \mathrm{mg}$; and 2 (0.9\%) use more than $150 \mathrm{mg}$ of methadone per day.

During treatment, patients were subjected to randomized diagnostic tests to evaluate methamphetamine and morphine use; the results are as follows:

Among the patients, 153 (66.5\%) had at least one positive test of morphine consumption during the treatment period; 27 (12\%) had at least consumed methamphetamine once. At the end of two last weeks, which led to discontinuation of treatment $37(16.1 \%)$ and $10(4.3 \%)$ of patients had positive morphine and methamphetamine tests respectively. The results of survival' rate in methadone maintenance treatment for patients participating in the project were as follows:

Out of 230 patients participated in this plan of 216 (93.9\%) individuals continued their treatment for more than a month. 146 (63.48\%) continued their treatment for more than three months, and 65 (28.36\%) remained in treatment for more than six months. Survival' rate of patients regarding continuation of treatment was also analyzed according to their age: Shortest retention in treatment was 7 days in which only one patient's kept his/her treatment program for only 7 days. 18 patients out of the 70 patients who were under 30, i.e. $25.7 \%$ of them were able to complete six months of treatment. In addition, 30 patients out of 97 patients aged 39 - 30 continued 
their treatment for six months (30.93\%); however, 17 out of 63 patients over 40 years old were able to continue their treatment for more than six months (29.98\%). Results of the survival' rates of patients continued their treatments according to their level of education are as follows:

15 patients (28.30\%) out of the 53 patients had under secondary school education, and 44 patients (27.67\%) with the grade between secondary school and diploma could maintain at treatment for at least six months; while 6 patients (33.33\%) out of 18 individuals with above diploma certificate continued their treatment for more than six months.

Survival rates in treatment based on marital status were also studied: 51 individuals (28.33\%) out of 180 married patients who lived with his/her spouse were able to continue their treatment for more than six months, and 14 patients (28\%) out of other 50 patients who stayed in other groups, referring before, regarding marriage were remaining more than six months in treatment. The results of investigation associated with positive test of morphine consumption, and maintaining in treatment were as follows:

43 patients (28.1\%) out of the 153 individuals who had at least one morphine positive test during the treatment could accomplish their six months' treatment; however out of 77 patients without any positive test, 22 patients (28.57\%) remained at their six months' treatment. Meanwhile, 61 patients (31.61\%) out of the 193 individuals who had no morphine positive test at the last two weeks period of their treatment course, could complete a six-month course of treatment; but only 4 patients (10.81\%) out of 37 individuals with a history of a positive test in the last two weeks of treatment remained in their treatment for six months. Moreover, the relation of positive test with respect to methamphetamine use and retention in treatment was evaluated: 4 patients (14.81\%) out of the 27 individuals who had at least one positive test of methamphetamine use during the treatment period had been able to continue treatment for up to six months. However, 61 patients (30.2\%) of those without any positive methamphetamine urine test have been able to complete their six months of treatment. In addition, 2 patients (20\%) out of 10 individuals who had positive amphetamine test at the last two weeks of treatment have been able to continue their treatment for six months and out of 220 patients who have not revealed positive test at the late two weeks, 63 patients (28.64\%) were retained at the treatment.

As shown from Table 1, it is clear that, women had 28\% less survival rate in their treatment than men.

In addition, those having family support had 2 times retention rate than others. The amount of methadone use is also an effective factor in survival rates of treatment. It was seen that those with less than $50 \mathrm{mg}$ of methadone use daily show more retention rate with respect to this treatment.

\section{Discussion}

In this study, survival rates in the first, second, and sixth month of treatment was $93.9 \%, 63.48 \%$, and $28.36 \%$ respectively. Survival rate in the first three months of this study is similar to other studies [1] [2] [4] [8]-[10];

Table 1. Relation between survival rates of treatment and sex, age, family support and methadone dose.

\begin{tabular}{|c|c|c|c|c|c|c|c|c|}
\hline \multirow{2}{*}{ Factor } & \multirow{2}{*}{$\beta$ factor } & \multirow{2}{*}{$\mathrm{SE}$} & \multirow{2}{*}{ Wald } & \multirow{2}{*}{$\mathrm{df}$} & \multirow{2}{*}{ Sig. } & \multirow{2}{*}{$\begin{array}{l}\text { Odd ratio } \\
\operatorname{Exp}(\mathrm{B})\end{array}$} & \multicolumn{2}{|c|}{$95.0 \%$ CI for $\operatorname{Exp}(B)$} \\
\hline & & & & & & & Lower & Upper \\
\hline Sex & -1.243 & 0.523 & 5.654 & 1 & 0.017 & 0.289 & 0.104 & 0.804 \\
\hline Family support & 0.669 & 0.187 & 12.851 & 1 & 0.000 & 1.953 & 1.354 & 2.815 \\
\hline $\begin{array}{c}\text { Age } \\
\text { (under } 30 \text { years) }\end{array}$ & & & 5.481 & 2 & 0.065 & & & \\
\hline $\begin{array}{c}\text { Age } \\
\text { (between } 30 \text { and 39) }\end{array}$ & 0.029 & 0.227 & 0.016 & 1 & 0.898 & 1.029 & 0.660 & 1.606 \\
\hline $\begin{array}{c}\text { Age } \\
\text { (above } 40 \text { years) }\end{array}$ & -0.409 & 0.217 & 3.544 & 1 & 0.060 & 0.664 & 0.434 & 1.017 \\
\hline $\begin{array}{l}\text { Methadone dose } \\
(<50 \text { mg per day) }\end{array}$ & & & 9.766 & 2 & 0.008 & & & \\
\hline $\begin{array}{c}\text { Methadone dose } \\
\text { (50 - } 99 \text { mg per day) }\end{array}$ & 0.224 & 0.515 & 0.189 & 1 & 0.663 & 1.251 & 0.456 & 3.431 \\
\hline $\begin{array}{l}\text { Methadone dose } \\
\text { (>150 mg per day) }\end{array}$ & -0.602 & 0.561 & 1.153 & 1 & 0.283 & 0.548 & 0.183 & 1.644 \\
\hline
\end{tabular}


however, the important point is that the retention rate is less in six months treatment. Patients stated financial problems as the main reason of their recurrence (31.9\%); which indicates that financial and career support play an important role in prevention [1]. $76.1 \%$ of the patients were established as those who gain methadone doses between 50 to $100 \mathrm{mg}$, indicating that the most common required dose for patients is in the same range.

In this study there was a significant relationship between gender and retention in treatment. The survival rate of women, comparing to men, is $28 \%$ less (P-value: 0.017 ). This relationship has also been proved in similar studies [1] [11]. This result indicated that in treatment there should be a special look for women than men and plan more supportive and non-medicinal interventions for them. Moreover, there was no significant relation between methadone dose used and survival rate in this study. Patients with daily dose of less than 50 mg methadone had a greater survival rate (P-value: 0.008 ). Therefore, it is necessary to exert more medicinal and supportive interventions for those who use higher doses of $50 \mathrm{mg}$. There found a significant relationship between family support and survival rate. People who had family support showed a survival rate that was 2 times in comparison to others (P-value: 0.000). This result draw this conclusion that training programs, family therapy, and gaining family support have a prominent impact on the healing process [1] [4] [8] [10] [12]. The highest survival rate was observed in patients who were between the ages of 30 to 39 years. Although there was a no significant relation there (P-value: 0.06). However, consistent with other studies it was shown that middle-age patients have a higher survival rate [1] [13]. This indicates that patients categorized in before-and-after middle age group may need more support. Patients with higher diploma education had more survival rate. However, no-significant relation found, yet consistent with other studies, education has a positive impact on therapeutic outcomes [1] [3] [14].

Patients who had a spouse and lived with them were more immanent in their treatment. In spite of showing no significant relation consistent with other studies, marital status play a positive role in retention [1] [4] [15]. Patients with at least one positive test for morphine and methamphetamine use during the treatment period, experienced lower rates of retention in treatment. Although no significant relation was found, it may be due to low sample size. Patients who had positive test of morphine during their two last weeks of treatment have significantly interrupted their treatment. This reflects the fact that in case of a positive urine test there should be more supportive endeavors to save the patients form potential risk saved treatment' cut down; Punitive approach would result in negative consequences. Patients who had positive test of methamphetamine during their two last weeks of treatment interrupt their treatment sooner; however, no significant relation was found and this may attributed to low sample size. From this fact that at the beginning of treatment only $0.9 \%$ of the patients had used methamphetamine but during treatment phase $12 \%$ of patients had positive urine methamphetamine use we may conclude that concurrent use of methamphetamine and methadone is one of the problems of methadone maintenance treatment. There should be more scientific management involved in order to solve such a problem.

In this study there was no prove for effectiveness of different parameters like type of drug, drug use method, duration of addiction, presence of addict in the family, type of prior therapies, jail history, and concomitant diseases regarding survival rates of treatment. In the same study, however, ineffectiveness of some of these components in the initial months of treatment was identified [1].

\section{Conclusions}

As mentioned earlier, MMT treatment is considered as a standard and reliable therapy for addiction treatment and there are many affecting factors regarding successful implementation of this approach. In this study, we examined a number of these components. One of the most important issues in methadone maintenance treatment is that the patient will stay in treatment till complete abstinence and do not exit it suddenly without discretion of the therapist.

Male gender, family support, amount of morphine consumption, and positive urine test of methadone are significantly related with survival in treatment. Age, education, marital status and positive urine test of methamphetamine are also among factors affecting in the treatment. Although these factors are not statistically significant, therapist should not ignore their effects. Because of the insufficiency of investigating sample size, it may remain some unidentified effects in this regard; hence, it is recommended that we should conduct a comprehensive study in order to recognize all factors affecting successful implementation of MMT treatment; consequently by using these factors, we may conduct successful treatment for patients. 


\section{Acknowledgements}

Hereby we acknowledge supports of Hygiene College and Medical New Technology Collage of Tehran University, Deputy Treatment of Yazd Medical Science University, personnel of addiction treatment centers in Yazd province, and all patients who participated in the study.

\section{References}

[1] Hosseini, F. (2010) Retention Rate in Methadone Maintenance Therapy. Journal of Shaheed Sadoughi University of Medical Sciences, 18, 152-158.

[2] Ippoliti, D., Davoli, M., Perucci, C.A., Pasqualini, F. and Bargagli, A.M. (1998) Retention in Treatment of Heroin Users in Italy: The Role of Treatment Type and of Methadone Maintenance Dosage. Drug and Alcohol Dependence, 52, 167-171. http://dx.doi.org/10.1016/S0376-8716(98)00091-X

[3] Booth, R.E., Corsi, K.F. and Mikulich-Gillbertson, S.K. (2004) Factors Associated with Methadone Maintenance Treatment Retention among Street-Recruited Injection Drug Users. Drug Alcohol Dependence, 74, 177-185. http://dx.doi.org/10.1016/j.drugalcdep.2003.12.009

[4] Peles, E., Schreiber, M. and Adelson, M. (2006) Factors Predicting Retention in Treatment: 10-Year Experience of a Methadone Maintenance Treatment (MMT) Clinic. Drug and Alcohol Dependence, 82, 211-217. http://dx.doi.org/10.1016/j.drugalcdep.2005.09.004

[5] Karimi Talabari, Z. (2013) Reasons of Methadone Maintenance Therapy Drop out in Clients of Iranian National Center for Addiction Studies (INCAS): A Qualitative Study. Iranian Journal of Psychiatry and Clinical Psychology, 18, 299309.

[6] John, M., Miichaell, G., Sttewarrt, D., Bestt, D., Farrrrellll, M. and Sttrrang, J. (1998) The Maudsley Addiction Profile: A Brief Instrument for Treatment Outcome Research. National Addiction Centre/Institute of Psychiatry Addiction Sciences Building Windsor Walk London.

[7] Zuana, J. and Steve, G. (2005) Pharmacology Biochemistry and Behavior. National Institute on Drug Abuse.

[8] Kaplan, H.I., Freedman, A.M. and Sadock, B.J. (2009) Comprehensive Textbook of Psychiatry. 9th Edition, University of Michigan, Williams \&Wilkins, 1380-1432.

[9] Fakhraie, S.A. and Babayance, A. (2007) Methadone a Good Experience of Maintenance Treatment in Iran. Addiction Journal, 1, 28-31.

[10] Strang, J. and Tober, G. (2003) Methadone Matters: Evolving Community Methadone Treatment of Opiate Addition Book. Informa Health Care, United Kingdom, 254.

[11] Miguel, D. (1997) Predictors of Patient Retention in a Newly Established Methadon Maintenance Treatment Programe. Addiction, 92, 1353-1360. http://dx.doi.org/10.1111/j.1360-0443.1997.tb02854.x

[12] Langendam, M.W., Van Brussel, G.H., Coutinho, R.A. and Van Ameijden, E.J. (2000) Methadone Maintenace and Cessation of Injecting Drug Use: Results from the Amesterdam-Cohort Study. Addiction, 45, 591-600. http://dx.doi.org/10.1046/j.1360-0443.2000.95459110.x

[13] Lejuez, C.W., Zvolensky, M.J., Daughters, S.B., Bornovalova, M.A., Paulson, A. and Tull, M.T. (2008) Anxiety Sensitivity: A Unique Predictor of Dropout among Inner-City Heroin and Crack/Cocaine Users in Residential Substance Use Treatment. Behaviour Research and Therapy, 46, 811-818. http://dx.doi.org/10.1016/j.brat.2008.03.010

[14] Ward, J., Hall, W. and Mattick, R.P. (1999) Role of Maintenance Treatment in Opioid Dependence. Lancet, 353, 221226. http://dx.doi.org/10.1016/S0140-6736(98)05356-2

[15] McKellar, J., Kelly, J., Harris, A. and Moos, R. (2006) Pretreatment and during Treatment Risk Factors for Dropout among Patients with Substance Use Disorders. Addictive Behaviors, 31, 450-460. http://dx.doi.org/10.1016/j.addbeh.2005.05.024 


\section{Appendix}

\section{Maudsley Addiction ProWle (MAP)}

A brief instrument for treatment outcome research.

SECTION A: MANAGEMENT AND OPERATIONAL INFORMATION

\begin{tabular}{|llll|}
\hline Programme/setting & & \\
Community & & & \\
drug/alcohol team & $\square$ & Inpatient programme & $\square$ \\
Community detox. & $\square$ Residential rehabilitation & $\square$ \\
General practitioner & $\square$ Prison programme & $\square$ \\
Advice, counselling & Other - describe & $\square$ \\
and information & $\square$ & & \\
Harm minimisation & $\square$ & \\
\hline
\end{tabular}

\section{Assessor:}

\begin{tabular}{|lr|}
\hline \multicolumn{2}{l|}{ Date of MAP interview } \\
D D \\
$\square \square$
\end{tabular}

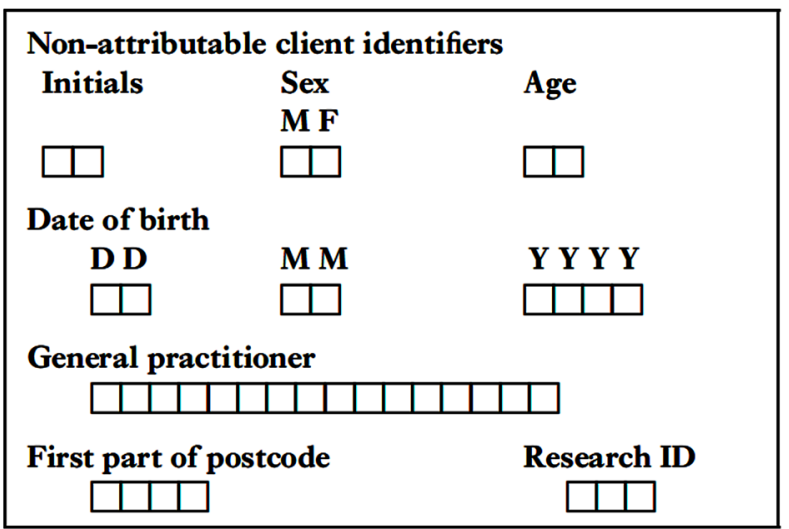

\begin{tabular}{|lll|} 
Interview point & \\
Intake $\quad \square$ & Departure \\
3 months $\square$ & +3 months \\
6 months $\square$ & +6 months \\
12 months $\square$ & +12 months \\
\hline
\end{tabular}

\begin{tabular}{llll|} 
Referral details & & \\
Self & $\square$ & HA & $\square$ \\
CDT/CAT & $\square$ & Vol. agency & $\square$ \\
GP & $\square$ & Probation & $\square$ \\
SSD & $\square$ & Other & $\square$ \\
\hline
\end{tabular}

\begin{tabular}{|llll|}
\hline Ethnicity & & \\
White (UK) & $\square \quad$ Black - African & $\square$ \\
Irish & $\square \quad$ Black - others & $\square$ \\
White (EU) & $\square$ Bangladeshi & $\square$ \\
Black - Caribbean & $\square$ Indian & $\square$ \\
Chinese & $\square \quad$ Pakistani & $\square$ \\
Other & $\square \quad$ Specify & $\square$ \\
\hline & & & \\
\hline
\end{tabular}

\section{SECTION B: SUBSTANCE USE}
(A) Enter whether used in the past 30 days
(B) [Card 2] Record number of days used in past 30 days
(C) Enter amount used on typical using day in past 30 days
(D) Record route(s) of administration

Note: Record grammes/money equivalent for amount consumed; probe fully for alcoholic drinks and record type(s), brand, size (e.g. small/large can; pint/half-pint; size measures for spirit). 
FREQUENCY OF USE IN THE PAST 30 DAYS

\begin{tabular}{|c|c|c|c|c|c|c|c|c|c|}
\hline $\begin{array}{l}1 \text { day } \\
\text { only }\end{array}$ & $\begin{array}{c}2 \text { days } \\
\text { only }\end{array}$ & $\begin{array}{c}3 \text { days } \\
\text { only }\end{array}$ & $\begin{array}{c}\text { Once every } \\
\text { week }\end{array}$ & $\begin{array}{l}2 \text { days } \\
\text { aweek }\end{array}$ & $\begin{array}{l}3 \text { days } \\
\text { aweek }\end{array}$ & $\begin{array}{l}4 \text { days } \\
\text { aweek }\end{array}$ & $\begin{array}{l}5 \text { days } \\
\text { aweek }\end{array}$ & $\begin{array}{l}6 \text { days } \\
\text { aweek }\end{array}$ & $\begin{array}{c}\text { Every } \\
\text { day }\end{array}$ \\
\hline \multirow[t]{3}{*}{1} & 2 & 3 & 4 & 9 & 13 & 17 & 21 & 26 & 30 \\
\hline & & $\begin{array}{c}\text { Oral } \\
1\end{array}$ & $\begin{array}{c}\text { Snort/sniff } \\
2\end{array}$ & $\mathrm{Sm}$ & $\begin{array}{l}\mathrm{e} / \text { chase } \\
3\end{array}$ & $\begin{array}{r}\text { Intrave } \\
4\end{array}$ & & & \\
\hline & & & Yes/No & $\begin{array}{l}\text { No o } \\
\text { past }\end{array}$ & $\begin{array}{l}\text { imes } \\
\text { days }\end{array}$ & $\begin{array}{l}\text { An } \\
\text { on a }\end{array}$ & $\begin{array}{l}\text { nt used } \\
\text { ical day }\end{array}$ & & $\begin{array}{l}\mathrm{e}(\mathrm{s}) \text { of } \\
\text { aistration }\end{array}$ \\
\hline
\end{tabular}
(1) Alcohol
(2) Heroin
(3) Illicit methadone
(4) Illicit benzodiazepineSpecify
(5) Cocaine powder
(6) Crack/rock cocaine
(7) Amphetamines

SECTION C: HEALTH RISK BEHAVIOUR

Injected drugs in the past 30 days?

Yes/No

If no injecting in the past 30 days skip to sexual behaviour items

(1) Days in the past 30 days injected drugs (days)

(2) Times injected on a typical day in past 30 days (times)

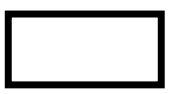

(3) Times injected with a needle/syringe already used by someone else (times)

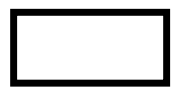

Had penetrative sex in the past 30 days and not used condom?

If no non-condom sex in the past 30 days skip to health items

(4) How many people had sex with and not used condom (people)

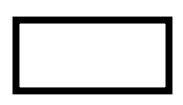

(5) Times had sex when not used condom (times) 
SECTION D: HEALTH SYMPTOMS

(1) Physical health symptoms

\begin{tabular}{|lccccc|}
\hline Past 30-day frequency & Never & Rarely & Sometimes & Often & Always \\
(a) Poor appetite & $\square$ & $\square$ & $\square$ & $\square$ & $\square$ \\
(b) Tiredness/fatigue & $\square$ & $\square$ & $\square$ & $\square$ & $\square$ \\
(c) Nausea (feeling sick) & $\square$ & $\square$ & $\square$ & $\square$ & $\square$ \\
(d) Stomach pain & $\square$ & $\square$ & $\square$ & $\square$ & $\square$ \\
(e) Difficulty breathing & $\square$ & $\square$ & $\square$ & $\square$ & $\square$ \\
(f) Chest pain & $\square$ & $\square$ & $\square$ & $\square$ & $\square$ \\
(g) Joint/bone pain & $\square$ & $\square$ & $\square$ & $\square$ & $\square$ \\
(h) Muscle pain & $\square$ & $\square$ & $\square$ & $\square$ & $\square$ \\
(i) Numbness/tingling & $\square$ & $\square$ & $\square$ & $\square$ & $\square$ \\
(j) Tremors (shakes) & $\square$ & $\square$ & $\square$ & $\square$ & $\square$ \\
\hline
\end{tabular}

(2) Psychological health symptoms 
SECTION E: PERSONAL/SOCIAL FUNCTIONING

In relationship with a partner in the past 30 days?

If no partner in the past 30 days skip to relatives items

(1) The number of days that you had contact with your partner

(i.e. saw them or talked to them on the telephone)

(2) On how many of these days was there conXict between you?

(i.e. had major arguments etc.)

Tick here if no relatives or no contact with any in the past month

(3) The number of days that you had contact with your relatives

(i.e. saw them or talked to them on the telephone)

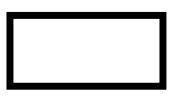

(4) On how many of these days was there conXict between you?

(i.e. had major arguments etc.)

Tick here if no contact with any friends in past month

(5) The number of days that you had contact with your friends

(i.e. saw them or talked to them on the telephone)

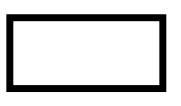

(6) On how many of these days was there conXict between you?

(i.e. had major arguments etc.)

(7) Days had paid work in past 30 days

(8) Days missed from work because of sickness or unauthorised absence
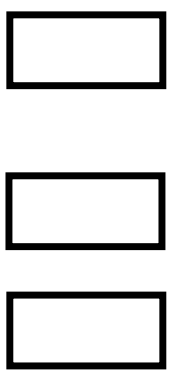

(9) Days formally unemployed in the past 30 days

(10) Crime involvement in the past 30 days

(a) Selling drugs
(b) Fraud/forgery
(c) Shoplifting
(d) Theft from a property
(e) Theft from a person
(f) Theft from a vehicle
(g) Theft of a vehicle




\section{END OF INTERVIEW}

(From Marsden, J., Gossop, G., Stewart, D., et al. (1998) The Maudsley Addiction ProWle (MAP): a brief instrument for assessing treatment outcome. Addiction, 93(12), 1857-1867. With permission from Blackwell Publishing and author.) 